\title{
Female spouses of injection drug users in Pakistan: a bridge population of the HIV epidemic?
}

\author{
S. Ahmad, ' J. Mehmood, ${ }^{2}$ A.B. Awan, ${ }^{3}$ S.T. Zafar, ${ }^{3}$ K. Khoshnood ${ }^{4}$ and A.A. Khan ${ }^{2,5}$
}

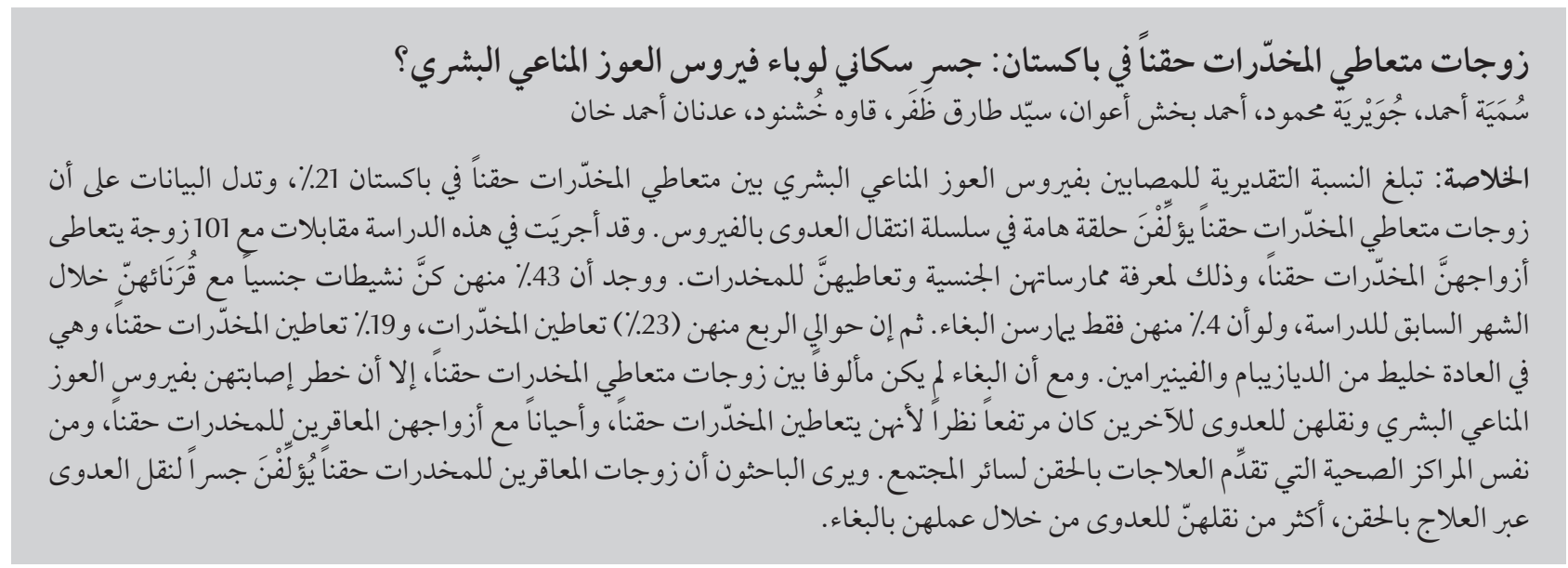

ABSTRACT An estimated 21\% of injection drug users (IDUs) in Pakistan are HIV-positive and data suggest that the spouses of IDUs may be a critical component of the HIV transmission chain. This study interviewed 101 spouses of male IDUs about their sexual practices and drug use. We found that $43 \%$ had been sexually active with their partners in the past month but only $4 \%$ reported selling sex. Almost a quarter (23\%) used drugs and $19 \%$ injected drugs, usually a combination of diazepam and pheniramine. Although sex work was infrequent among spouses of IDUs, their risk of contracting HIV and transmitting it to others was high because they received injection drugs, sometimes along with their IDU husbands, from the same health centres that provided therapeutic injections to the rest of the community. IDU spouses may thus serve as a bridge group via therapeutic injections, rather than via sex work.

Épouses de consommateurs de drogues injectables au Pakistan : un maillon de la chaîne de transmission de I'épidémie du VIH dans la population?

RÉSUMÉ Il a été estimé que $21 \%$ des consommateurs de drogues injectables au Pakistan étaient positifs au VIH et les données laissent à penser que les épouses de ces derniers pourraient être un maillon critique de la chaîne de transmission du VIH. Pour la présente étude, 101 épouses de consommateurs de drogues injectables ont été interrogées au sujet de leurs pratiques sexuelles et de leur consommation de drogues. Nous avons découvert que $43 \%$ d'entre elles avaient eu une activité sexuelle avec leur partenaire au cours du mois précédent, mais que seulement $4 \%$ déclaraient vendre des services sexuels. Près d'un quart de ces femmes (23\%) consommaient des drogues et $19 \%$ des drogues injectables, le plus souvent une association de diazépam et de phéniramine. Même si le commerce du sexe était peu fréquent chez les épouses de consommateurs de drogues injectables, le risque d'infection par le VIH et de transmission à des tiers était élevé car elles recevaient des drogues injectables, parfois avec leur époux consommateur de ces drogues, dans les mêmes centres de santé fournissant des injections de médicaments à l'ensemble de leur communauté. Les épouses de consommateurs de drogues injectables pourraient représenter un maillon de la chaîne de transmission du VIH par l'intermédiaire des injections de médicaments, et non par le commerce du sexe. 


\section{Introduction}

The human immunodeficiency virus (HIV) epidemic in Pakistan has become well established among injection drug users (IDUs) [1-3]. In 2008, the national AIDS control programme estimated that there were about 100000 street-based IDUs in Pakistan, of whom nearly $21 \%$ had HIV infection [2,3]. More recently male and transgender sex workers have shown early evidence of epidemic transmission, particularly in cities where they have the most sexual contacts with IDUs [2,3]. At present, there is little evidence of HIV transmission to the general population, and it is unclear which subgroups will provide the bridge for transmission from IDUs to the population.

About 95\% of IDUs in Pakistan are sexually active and $38 \%$ have a regular sexual partner [3]. A recent modelling study demonstrated that IDUs were more likely to transmit HIV to their spouses and regular sex partners than to sex workers in any city in Pakistan [4]. This is consistent with regional experience. A 2000 study showed that $45 \%$ of wives of HIV-positive IDUs from Manipur, India were also HIV infected [5]. However, it is unclear if the spouses and regular partners of IDUs are merely at risk of HIV infection or if they play a bridging rolein theonward transmission of the infection to others. To date, few studies provide information about this vulnerable population, and none have examined the vulnerabilities or HIV transmission potential of the spouses of IDUs in Pakistan.

We conducted this study in Faisalabad and Lahore where the nongovernmental organization Nai Zindagi (New Life) provides harm reduction services for IDUs. Lahore is the second most populous city in Pakistan, with over 3000 IDUs, an estimated 4\% of whom have HIV infection. Faisalabad is the third most populous city, with over 8000 IDUs, $13 \%$ of whom are estimated to be HIV-positive [3]. The purpose of this study was to inquire about infection risk, sexual habits and drug use by spouses and regular partners of male IDUs to understand whether these women have a role in the HIV transmission chain from IDUs to the general population. Furthermore, we wished to ascertain what the mode of such transmission would be, if it were to occur. Our hypothesis, based on discussions with IDU harm reduction workers, was that transmission of HIV was most likely via commercial sex, which many of the IDUs' spouses were believed to be engaging in.

\section{Methods}

\section{Sample}

Nai Zindagi NGO has 4733 registered IDUs in Lahore and 4696 in Faisalabad, compared with surveillance estimates of 3350 and of 8030 respectively. At least $60 \%$ of all IDUs in these cities are using these services - over-registration of IDUs in Lahore is high as names of IDUs are not removed once they move away, and turnover of IDUs is high - therefore the probability of selection bias based on service seeking was considered low.

We used the NGO client records to identify married male IDUs from urban and peri-urban areas of Lahore and Faisalabad, Pakistan, and asked them to introduce us to their spouses or long-term sex partners. Each male IDU reported only 1 long-term partner and therefore only 1 subject was interviewed per IDU client. A total of 102 women were recruited consecutively by randomly selecting their husbands' names from the NGO records. We interviewed 97 of these subjects and excluded the 5 women who reported not living with their husbands currently or who had incomplete information. We also recruited 4 female sex workers who had been identified by local NGOs as having long-term IDU sexual partners, giving a total of 101 subjects.
Interviewees were compensated for transportation when applicable but no other compensation was given.

\section{Data collection and analysis}

Interviews were conducted during June and July 2007. The study questionnaire incorporated components from internationally standardized instruments [6], including basic background and socioeconomic information, sexual history/risk factors, perceived risk of HIV and history of testing, plus separate modules for drug users and female sex workers.

Both the basic background information and sexual history questionnaires were taken from the AIDS/CAPS/ WHO counselling and efficacy study (counselling and testing baseline instrument) survey, which has been internationally validated [6]. Basic background information collected included age, marital status, number of living children, current living situation (including details about household utilities), number of years spouse has been using drugs, number of living inhabitants, job status and information.

We assessed details of our subjects' sexual and drug histories using a separate qualitative instrument that was derived from Canada Africa Partnership's Client qualitative guide [6]. It included details about the frequency of sexual encounters, condom use, relationships and drug use history, including questions about length and frequency of drug use, moods and attitude toward drugs, experiences and details of the last encounter, HIV risk and history of testing, and questions about hygiene and the acquisition of drugs.

The research team filled out the survey during the interview, which was also tape-recorded. Interviews were conducted in our drop-in facility in Lahore or at subjects' homes. We ensured privacy by allowing only the subject and research team into the interview room. A consent form was read and explained to the interview subjects, which 
explained that any identifying information about them would be destroyed and that the recordings we made would not have their name, husband's name, or other identifying information within it. The subjects, if literate, were allowed to read the consent form and sign it. Illiterate subjects were asked to repeat the information given and thumb-print the consent form. All procedures including recruitment and consent were approved by human investigation committees from both Yale University and Nai Zindagi's Institutional Review Board in Pakistan. The interviews took 15-35 minutes each.

We analysed the data using descriptive statistics and univariate analysis with SPSS, version 13.

\section{Results}

The women interviewed had a mean age of 35 years and nearly all were currently married. Most (62\%) were employed, a quarter provided the sole income for their households and only 29\% received any income support from their spouse (Table 1).

\section{Sexual behaviour with spouses}

Our subjects reported infrequent sex with their spouses, with a mean of 1.01 sex acts per month (median: 0, range: $0-15$ ) and $57 \%$ reported having no sex with their spouse in the past month. Only 17\% of women reported using a condom during the last sex act with their spouse. Four reported anal sex of these, 1 used a condom. Five knew that their husbands had had sex with someone else in the past 6 months. One-third (33\%) felt it would be easy or very easy to ask their spouses to use a condom.

\section{Sex work}

Four women (4\%) from the main (consecutive recruitment) sample reported selling sex to supplement their income. We interviewed an additional 4 women

\begin{tabular}{|c|c|}
\hline Variable & Value \\
\hline Age [mean \& range, years] & $35(18-66)$ \\
\hline \multicolumn{2}{|l|}{ Marital status (\%) } \\
\hline Married & 94 \\
\hline Divorced & 1 \\
\hline Widowed & 0 \\
\hline Separated & 1 \\
\hline Not married & 1 \\
\hline \multicolumn{2}{|l|}{ Spouse [mean \& range, years] } \\
\hline Cohabitation with current spouse/sexual partner & $11(0.2-42)$ \\
\hline Spouse's use of drugs & $7(0.6-30)$ \\
\hline \multicolumn{2}{|l|}{ Household [mean \& range] } \\
\hline No. of living children & $4(0-12)$ \\
\hline No. of cohabitants in house & $7.5(0-35)$ \\
\hline \multicolumn{2}{|l|}{ Income (\%) } \\
\hline Receive regular financial support from spouse/partner & 29 \\
\hline Sole provider of household income & 25 \\
\hline \multicolumn{2}{|l|}{ Employment (\%) } \\
\hline Employed & 62 \\
\hline Feel that current job is stable & 43 \\
\hline \multicolumn{2}{|l|}{ Payment for medical expenses (\%) } \\
\hline Out-of-pocket & 79 \\
\hline Utilized free/clinical services & 15 \\
\hline Other & 4 \\
\hline \multicolumn{2}{|l|}{ Risk behaviour (\%) } \\
\hline Use drugs & 23 \\
\hline Inject drugs & 19 \\
\hline Sell sex & 4 \\
\hline
\end{tabular}

who had been identified by the $\mathrm{NGO}$ as both a sex worker and spouse of a drug user. Only 1 of the 8 sex workers had used condoms regularly with clients; 4 claimed that condoms gave them infections and so did not use them. These women charged about US $\$ 2$ per sex act. Most of them (7/8) used drugs.

\section{Sex and protection knowledge}

Almost half (48\%) of the women had never heard of the term "HIV". Of these, $22 \%$ felt they were highly unlikely to be HIV infected and only $7 \%$ felt they were highly likely to acquire HIV. Only 9 (9\%) women had ever been tested for HIV; all the tests had been negative. Only 13\% had ever discussed HIV risk with their IDU husbands and over half did not feel that they could have this discussion (Table 2).

\section{Drug use}

Drugs were used by 22 (23\%) women, including $18(19 \%)$ whoinjected (Table 3). Most of the injection users (17/18) went to a local doctor/quack to receive injections of a pharmaceutical cocktail (diazepam and pheniramine); only 1 injected herself. The women receiving injections received an average of 20 (5-60) monthly and 13/17 had started injecting following their husbands. Only $2 / 17$ ensured that the syringes they used were new; all others reported that the injection was prepared behind a curtain or door and they were not sure if it was prepared with sterile techniques 


\begin{tabular}{|c|c|}
\hline \multicolumn{2}{|c|}{$\begin{array}{l}\text { Table } 2 \text { Human immunodeficiency } \\
\text { virus (HIV) risk perception and testing } \\
\text { among the spouses of male injection } \\
\text { drug users }\end{array}$} \\
\hline Variable & $\begin{array}{c}\text { Subjects } \\
(n=97) \\
(\%)\end{array}$ \\
\hline Does not know about HIV & 48 \\
\hline \multicolumn{2}{|l|}{ Perception of HIV risk } \\
\hline Highly unlikely & 22 \\
\hline Unlikely & 10 \\
\hline Moderate & 4 \\
\hline Likely & 9 \\
\hline Highly likely & 7 \\
\hline $\begin{array}{l}\text { Previously tested for } \\
\text { HIV }\end{array}$ & 9 \\
\hline $\begin{array}{l}\text { Discussed risk with } \\
\text { spouse }\end{array}$ & 13 \\
\hline \multicolumn{2}{|l|}{$\begin{array}{l}\text { Difficulty in asking spouse } \\
\text { to use condom }\end{array}$} \\
\hline Very easy & 18 \\
\hline Easy & 16 \\
\hline Difficult & 11 \\
\hline Very difficult & 5 \\
\hline $\begin{array}{l}\text { Does not use and would } \\
\text { not ask }\end{array}$ & 52 \\
\hline
\end{tabular}

or with a new syringe. Besides diazepam, a few smoked or inhaled heroin $(n=2)$ and marijuana $(n=3)$. Finally, all but 1 female sex worker interviewed admitted to using drugs.

Most of the women had been taking drugs for more than 1 year. Some had not realized that their husbands were IDUs until they themselves started to go to the doctor each evening and saw their husbands waiting in line for the injection. One woman said, "Once I started going regularly, it suddenly occurred to me why my husband would disappear each evening. It made a lot more sense."

\begin{tabular}{lrcc}
\hline Table 3 Types of drugs used by the spouses of male injection drug users \\
\hline Drug & No. & $\begin{array}{c}\% \text { of all subjects } \\
(\boldsymbol{n}=\mathbf{9 7})\end{array}$ & $\begin{array}{c}\text { \% of those using } \\
\text { drugs } \\
(\boldsymbol{n}=\mathbf{2 2})\end{array}$ \\
Diazepam and pheniramine & 18 & 18 & 78 \\
Heroin & 3 & 2 & 9 \\
Marijuana & 3 & 3 & 13 \\
Total & 22 & 23 & 100 \\
\hline
\end{tabular}

Most of the women were aware that they were IDUs. Many had started drugs to control actual physical pain but were now in severe pain without drugs. They accepted the idea of having drugs every other day or every week in order to feel productive or well and felt that they could not function or do much without drugs. They had the "routine built into their lives to go to the doctor". One woman said, "Sometimes when I am feeling ill, I go to the doctor twice a week. After my injection, I go to sleep, then wake up and feel fresh. I am able to wash my children's clothes, make food, and do my work. The injection makes it easier." Another woman who injected daily claimed, "On the days I don't have the injection, I have no peace. I work all day, not only my own work but also my mother-in-law's too. I get very tired and need it (drugs). I take it right before bed and go to sleep. Without it, I am also unable to pray. At least when I take it, the next morning, I am able to pray and

Reasons for beginning drug use were varied. "We work outside on the farm and go through a lot of pain at the end of the day", one woman said. Her husband had aches and pains throughout his body and decided to go more frequently to get injections. She said that soon after her husband began injecting, her body began to ache as well and she decided that she would start injecting. Regardless of the original reason they began injecting, all the women felt that they must continue injecting since they could not live comfortably without it. begin my work."

\section{Discussion}

We found that IDUs' spouses in this study were at moderate risk of acquiring HIV from their husbands via infrequent but unprotected sexual intercourse. While the overall numbers of sexual encounters were few, the low rate of condom use and HIV protection knowledge are concerning, given that an estimated 21\% (range: $0 \%-52 \%$ ) of all IDUs in Pakistan are HIV infected $[1-3]$. However, it is useful to know that many women $(33 \%)$ perceived it easy to ask their partners to use condoms. Many of these women (and some of their IDU husbands) received frequent injections from community providers who may use the same equipment to inject others in the community. This may be an important route for transmission of HIV from IDUs to their wives to the general public. Finally, a minority of these women also sold sex. Both community-based injections and sex work expand their HIV risk networks to include IDUs, clients of sex workers and community members. This is the first such study among IDUs' sexual partners in Pakistan and among the first in the region.

Prior to this study, anecdotal reports had suggested that sex work among IDUs' spouses was common, raising concern that IDUs' spouses may be an important bridging group [7] in $\mathrm{Pa}$ kistan. Very few of the women (4\%) reported that they sold sex. However those that did charged some of the lowest rates nationwide (Rs 100 versus the national median of Rs 200) [8] and virtually never used condoms. It is difficult to draw more inferences due to the small number of female sex workers in our sample.

Almost a quarter of our subjects used drugs and 19\% injected. Of these, the majority went to local doctors or quacks for injections (usually of a cocktail of phenirimine and diazepam). Diazepam is readily available in Pakistani pharmacies, who sometimes sell it without a 
prescription. Many of our IDU clients describe that diazepam produces a different kind of a "high" from opioids and crave it for itself.

Although the injections may have started for medical indications (albeit incorrect ones), these women eventually became addicted and went for injections regularly. In addition, $7 / 8$ women who sold sex also used drugs, increasing their exposure.

Almost none of our subjects were sure if the injections they received were sterile or not. Since medical practice is unregulated, many unqualified people set up practices in Pakistani communities and over time become indistinguishable to their clients from qualified physicians. These and many medical doctors prescribe/give injections extensively for a variety of medical ailments [9] and it has been shown that local residents from periurban communities may receive between 8 and 14 therapeutic injections annually $[10,11]$. Frequent injections by our subjects and their husbands and the high frequency of therapeutic injections in some Pakistani communities suggest that the potential for HIV or HCV transmission from IDUs to their wives and onto other members of the same communities. This route of bridging of
HIV transmission has been observed elsewhere [12-14]. Since HIV [1518] (and hepatitis C [19]) transmits more efficiently through injections than via sex and because therapeutic injections are so common in Pakistan [8-11,20-22], the overall exposure of communities to these viruses may be far greater from unsafe therapeutic injections than from commercial or non-commercial sex.

There are several limitations to our study. Some of the women were identified as sex workers by the Nai Zindagi team, but did not discuss their sex work during the interview and therefore were not included among sex workers for our study. Strong cultural taboos and fear of discrimination or persecution inhibit discussion of the sex trade and non-marital sex in Pakistani society. This may have resulted in fewer women discussing their sex trade, particularly since they were accessed via the NGO that provides harm reduction services to their husbands. The same may apply to drug histories. We suspected that many women felt uncomfortable discussing their sexual and drug histories during the interview, despite extensive explanation and attempts at establishing rapport, leading to under-reporting of sexual contacts and drug use among our subjects. Conducting additional interviews over time with the same subjects could help to establish trust and obtain more accurate information. In addition, our study recruited a small number of subjects from 2 cities. The sample size may not have been sufficient to assess aspects of drug use and the sex trade sufficiently, and local cultural diversity may mean that similar studies will have to be repeated in other cities to understand these nuances and intercity variations. Finally, as the NGO identified subjects who utilized their harm reduction services, the results from this research may not be generalizable to other IDUs.

Our findings suggest the need for interventions that reduce the reliance of IDUs' spouses on community injectors and for services that provide psychological support and enhance IDUs' skills or provide opportunities to enable them to deal with the economic hardship imposed on them by their husbands' drug use. A wider issue is that better injection practices need to be promoted in Pakistan, which has possibly the highest frequency of therapeutic injections in the world. Further research should study aspects of syringe and sexual networks of spouses of IDUs in order to understand their role in transmission of HIV in Pakistan.

\section{References}

1. HIV-AIDS surveillance project of Pakistan (HASP): pilot round. Islamabad, Pakistab, National AIDS control programme of Pakistan, 2005.

2. HIV-AIDS surveillance project of Pakistan (HASP): round 1. Islamabad, Pakistan, National AIDS control programme of Pakistan, National AIDS Control Programme of Pakistan, 2006.

3. HIV-AIDS surveillance project of Pakistan (HASP): round 2. Islamabad, Pakistan, National AIDS control programme of Pakistan, National AIDS Control Programme of Pakistan, 2008.

4. HIV risk in spouses of IDUs and sex workers in Pakistan. Presented at the 17th meeting of the International Society for Sexually Transmitted Diseases Research (ISSTDR), Seattle, Washington, 30 July-1 August 2007.

5. Panda $S$ et al. Transmission of HIV from injecting drug users to their wives in India. International Journal of STD and AIDS, 2000, 11:468-473.

6. Coates TJ, The Voluntary HIV-1 Counseling and Testing Efficacy Study Group. Efficacy of voluntary HIV-1 counselling and testing in individuals and couples in Kenya, Tanzania, and Trini- dad: a randomised trial. The Voluntary HIV-1 Counseling and Testing Efficacy Study Group. Lancet, 2000, 356:103-112.

7. Aral SO. Behavioral aspects of sexually transmitted diseases: core groups and bridge populations. Sexually Transmitted Diseases, 2000, 27:327-328.

8. National AIDS control programme. Family Health International/Pakistan Medical and Research Council/National Study of Sexual and Reproductive Tract Infections, 2004.

9. Janjua NZ, Akhtar S, Hutin YJ. Injection use in two districts of Pakistan: implications for disease prevention. International Journal for Quality in Health Care, 2005, 17:401-408.

10. Pasha $\mathrm{O}$ et al. Household members of hepatitis $\mathrm{C}$ virusinfected people in Hafizabad, Pakistan: infection by injections from health care providers. Epidemiology and Infection, 1999, 123:515-518.

11. Khan AJ et al. Unsafe injections and the transmission of hepatitis $B$ and $C$ in a periurban community in Pakistan. Bulletin of the World Health Organization, 2000, 78:956-963. 
12. Brewer DD et al. Investigating iatrogenic HIV transmission in Ugandan children. Journal of Acquired Immune Deficiency Syndromes, 2007, 45:253-254.

13. Brody $\mathrm{S}$ et al. Evidence of iatrogenic HIV transmission in children in South Africa. BJOG, 2003, 110:450-452.

14. Correa M, Gisselquist D. Routes of HIV transmission in India: assessing the reliability of information from AIDS case surveillance. International Journal of STD and AIDS, 2006, 17:731-735.

15. Hudgens MG et al. Estimating the transmission probability of human immunodeficiency virus in injecting drug users in Thailand. Applied Statistics, 2001, 50:1-14.

16. Hudgens MG et al. Subtype-specific transmission probabilities for human immunodeficiency virus type 1 among injecting drug users in Bangkok, Thailand. American Journal of Epidemiology, 2002, 155:159-168.

17. Kaplan EH, Heimer R. A model-based estimate of HIV infectivity via needle sharing. Journal of Acquired Immune Deficiency Syndromes, 1992, 5:1116-1118.
18. Gray RH et al., Rakai Project Team. Probability of HIV-1 transmission per coital act in monogamous, heterosexual, HIV-1-discordant couples in Rakai, Uganda. Lancet, 2001, 357:1149-1153.

19. McMahon JM, Pouget ER, Tortu S. Individual and couple-level risk factors for hepatitis $\mathrm{C}$ infection among heterosexual drug users: a multilevel dyadic analysis. Journal of Infectious Diseases, 2007, 195:1572-1581.

20. Luby S. Injection safety. Emerging Infectious Diseases, 2001, 7(Suppl.):535.

21. Raglow GJ, Luby SP, Nabi N. Therapeutic injections in Pakistan: from the patients' perspective. Tropical Medicine \& International Health, 2001, 6:69-75.

22. Luby $\mathrm{S}$ et al. Long-term improvement in unsafe injection practices following community intervention. International Journal of Infectious Diseases, 2005, 9:52-59.

\section{HIV surveillance in the Middle East and North Africa: a handbook for surveillance planners and implementers}

This handbook is aimed at surveillance officers and programme managers. It is designed to assist them in the planning and implementation of key components of a surveillance system for HIV infection and AIDS in a region where lowlevel and concentrated HIV epidemicscurrently predominate. It focuses primarily on the components of surveillance systems that track HIV prevalence and related risk behaviour among most-at-risk populations over time.

The full text of this handbook is available at http://www.emro.who.int/publications/Book_Details.asp?ID=1099 